\title{
Stability of Cereal Crops to Drought and Saline Stress in Vivo and in Vitro
}

\author{
Nina Terletskaya, Nina Khailenko and Kabl Zhambakin \\ Institute of Plant Biology and Biotechnology, Almaty 050040, Kazakhstan
}

Received: August 01, 2012 / Accepted: December 17, 2012 / Published: February 28, 2013

\begin{abstract}
Complex research is devoted to basic non-specific stress-reactions caused by abiotic factors such as drought and salinity in vivo and in vitro. A comparative physiological, biochemical and cytogenetic analysis was performed and showed the peculiarities of growth and viability on various (cellular, tissular, organismic) levels of plants structural arrangement at stress conditions. Determined the parameters of the growth, ion balance, the content of free proline, superoxide dismutase activity and conducted the cytological studies. The commonness of cytological reactions of plant cells to abiotic stress was revealed. The considerable positive correlation relationships between growth of callus biomass and increases of primary roots number under abiotic stressess, between growth of callus biomass and capacity for survival of seedlings under osmotic stress were registered. Such correlation tells about comparability of stress tolerance valuation at different levels of plants structural arrangement. The considerable negative correlation between $\mathrm{K}^{+} / \mathrm{Na}^{+}$ions relations and percent increase of free proline in calluses were showed. Physiological and biochemical indicators of abiotic stresses impact on plants cells and tissues, such as SOD activity and $\mathrm{K}^{+} / \mathrm{Na}^{+}$ions correlation were noted. These indicators are effective as metabolic markers in the course of testing and selection of stress-resistant cereals in vivo and in vitro.
\end{abstract}

Key words: Cereals, osmotic stress, salt stress, in vivo, in vitro.

\section{Introduction}

Adverse environment renders negative impact on plants growth and productivity in the vast territories of Kazakhstan. In the result crop products are harvested with significant loss thus inflicting extensive damage to the national economy. This is why the search and development of methods improving plants sensitivity to stress is treated as an affair of national importance.

It is known that stress resistance mechanisms occur at various levels of biological organization: cellular, organismic and population levels. Biochemical processes form cellular level of resistance. Combination of cell response, transport of water, ions and metabolites, cell-to-cell cooperation are the constituents of tissular and organismic levels. Plants

Corresponding author: Nina Terletskaya, Ph.D., research fields: physiology and biotechnology of cereals. E-mail: teni02@mail.ru. interaction in the stressed cenosis is the basis of population sensitivity level. And plants vital activity under stress is only possible if a plant body is capable of sufficient resistance at any of the levels.

Negative impact of abiotic stresses to a plant is complex. Droughts suggest at least osmotic and thermal components, and salinization includes at least three components: osmotic, toxical and specific salinization.

Osmotic effect of salinization, the same as draught effect, is shown in a decreased water uptake and adverse changes of water-salt metabolism in cells and tissues, toxical effect is expressed in aggravating of salt impact by redundant accumulation of ions in cells cytoplasm, whereas specific effect of salts is generally estimated by anionic heterogeneousness manifested in morpho-physiological and biochemical changes in plants, such as, for example, accumulation of various antioxidants in stressed conditions and activation of 
antioxidative ferments, primary purpose of which consists in suppressing increased levels of free radicals so that they carry out productive biological functions without bring too much damage to a plant body $[1,2]$.

In addition to specific impact-dependant and species-dependant response of plants, nonspecific cells response occurring under effect of any adverse factor is an important constituent of plants resistance to effects of ambient stress factors. The essence of nonspecific response mainly consists of those changes which are seen in the membranaceous formations of cells. Because membranes, being a natural barrier, are the first ones to encounter the impact of stress factors and they serve as primary targets for initial impact of stresses and the first line of defense. Plasma membranes, being selectively penetrable barriers, play a key role in cytoplasm ionic content regulation with the help of ATP-pumps, channel proteins and ionic transporters [3]. Membrane transport alteration under stress is one of the most important responses of plant cells aimed at homeostasis sustention and regeneration [4].

There are a number of mechanisms existing in the plants which ensure ions detoxification and resistance to the stress they induce. In general, these mechanisms may be subdivided into two groups: (1) restriction of ions access to cytozole; (2) alteration of cells metabolism aimed at reduction of ions toxic effect and their removal from plant bodies [5].

There is an opinion that ionic homeostasis regulation at the plasma membrane level, specifically in cases of high concentration of sodium chloride in the ambient environment, is typical to all genotypes [6].

Cells osmotic regulation may be performed due to compartmentalization of ions $\left(\mathrm{Na}^{+}, \mathrm{K}^{+}\right.$and others) or due to formation by the plants of their own organic compounds, which provide indispensable for water transport sustention intracellular osmotic potential $[4,7]$. Many plants, as a response to a wide range of abiotic and biotic stresses, may accumulate in their cells low-molecular metabolites (osmolites), which are capable of providing a protective effect under extreme salinization or drought conditions. Osmolites accumulation in cells occurs by way of energy-dependent transport from external medium or due to a change in speed of their synthesis and breakdown $[8,9]$. Proline, being one of the most typical osmolites, is presently the most explored protector and osmotic regulator [10]. Often an excessive accumulation of free proline may serve as an expressive stress indicator [11]. A big number of surveys of proline synthesis in plants were dedicated to the proline's ability to evoke osmotic regulation, stabilize subcellular structures and decrease free radicals content. However, proline accumulation may decrease also cellular oxidation processes induced by adverse conditions thus securing energy required for cells restoration. Even insignificant increase in proline biosynthesis under stressed conditions may impact NADP content in cells and preserve $\mathrm{NAD}(\mathrm{P})^{+}$ /NAD(P)H balance at a level comparable with metabolism under normal conditions [12]. This is why enhancement of proline-forming ability of plant cells, tissues and members under abiotic stress conditions attracts immense interest.

Cells energy consumption increases in stressed conditions and breathing efficiency increases as well. Breathing efficiency enhancement in its turn is related to structural and functional modifications of mitochondrial system due to stress. It should be noted that a certain part of damages occurring under salt stress conditions are due to ROS (reactive oxygen species) formation in a stressed cell, which then cause damages to membranes and photosystems. ROS impact brings oxidation of important cellular components, such as lipids and DNA, which results in death of cells either due to apoptosis, when cells internal content degrades to non-toxic decay products, or due to necrosis, when oxidative shock impact is too strong [13]. 
Presently available data show that one of the sources of ROS under stressed conditions is mitochondria and chloroplasts. Plant cells have a strong oxidative stress response mechanism. This mechanism includes such ferments as superoxide dismutase, catalase, peroxidases, as well as non-enzymatic defense mechanisms, such as a-tocopherol, ascorbate etc. Accumulation of various antioxidants under stressed conditions and activation antioxidative enzymes may be viewed as a general specific defense reaction of cells under salt stress [14, $15]$.

One of the possibilities of a comprehensive approach to stress resistance assessment may combine in vivo and in vitro assessment methods provided that such methods are comparable.

Taking into account plant biotechnologies development, cellular technologies may be deemed to form at least an effective add-on to the traditional plant breeding techniques or, at most, may serve as an alternative method.

The goal of this present study was to implement a comparative analysis of the physiological and cytogenetic peculiarities of cereal crops growth and vital capacity at various (cellular, tissular, organismic) levels of plants structural arrangement under salt and osmotic stress conditions in vitro and in vivo.

\section{Materials and Methods}

\subsection{Materials of Investigation}

The working collection for draught- and salt-resistance assessment included sort specimens of barley and wheat, which were provided by various plant breeding centers and which had shown various performances under abiotic stresses (Table 1).

\subsection{Investigation Methods}

Methods of Udovenko [16] and Terletskaya et al. [17] served the basis for laboratory assessment of 10-day barley and wheat seedlings under artificial draught and salinization conditions. Callus tissue cultivation was made in accordance with the method of Gaponenko [18]. In vivo, stress conditions were created using saccharose solution $(15.8 \%$ for barley and $17.6 \%$ for wheat) or $\mathrm{NaCl}$ solution (1.68\%) for seedlings cultivation for a period of $72 \mathrm{~h}$. In vitro,

Table 1 The list of lines of barley and wheat used on this work.

\begin{tabular}{lll}
\hline Lines & Field resistance & Received from selection centre, city, country \\
\hline Barley & & \\
\hline Rannyi 1 & Salt-resistant & Lavrentyev ICIG, Novosibirsk, Russia \\
Polarnyi 14 & Salt-resistant & $-/ /-$ \\
St-33 & Salt-resistant & $-/ /-$ \\
St-39 & Salt-resistant & $-/ /-$ \\
$74 / 2-4$ & Salt-sensitive & $-/ /-$ \\
$75 / 1-5$ & Salt-sensitive & $-/ /-$ \\
K-30356 & Salt-sensitive & $-/ /-$ \\
K-14220 & Salt-sensitive & $-/ /-$ \\
Dnepr.435 & Draught-resistant & NPC GP, Almalybak, Almaty, Kazakhstan \\
Odessk.100 & Draught-sensitive & NPC GP, Almalybak, Almaty, Kazakhstan \\
\hline Wheat & & \\
\hline Akmola 2 & Draught-resistant & Baraev NPC GF, Shortandy, Kazakhstan \\
Tselinnaya 3C & Draught- resistant & Baraev NPC GF, Shortandy, Kazakhstan \\
Otan & Draught- and Salt-resistant & IBBP, Almaty, Kazakhstan \\
Stepnaya 15 & Draught-resistant & IBBP, Almaty \\
Kazakhstanskaya 10 & Draught-resistant & NPC GP, Almalybak, Almaty, Kazakhstan \\
Eritrospermum 841 & Draught-resistant & South-East RSI, Saratov, Russia \\
\hline
\end{tabular}


conditions were created by adding polyethyleneglycol (PEG-6000) or $\mathrm{NaCl}$ to nutrient solution in concentrations $20 \%$ and $1.5 \%$ respectively, exposure period was equal to one month. Callus tissues growth parameters under salt stress conditions were assessed in terms of callus biomass gain. Resistance capacity of seedlings and callus tissues under modeled stress conditions was assessed by relative values of growth index and species biomass gain in percentage to the same figures registered in control conditions. Definition of the content by ions $\mathrm{K}^{+}, \mathrm{Na}^{+}$and $\mathrm{Ca}^{2+}$ in roots and leaves of wheat was spent on atom-absorbing spectrophotometer AAS-1 at length of a wave accordingly 766.5, 589.2 and $422.7 \mathrm{~nm}$ [19]. Free proline content was assessed based on the method of Bates [20]. Superoxide dismutase ferment activity was determined with the help of the spectrophotometric method of Jiang [21]. Pollen fecundity and vital capacity was determined based on the method of Trankovskiy [22]. Cytological examination was carried out with squash preparation under the method of Pausheva [23]. All experimental data were exposed to the statistical analysis on B.A. Dospehov [24]. To calculate the correlation coefficient $(r)$ using the equation: $\mathrm{p}_{\mathrm{x}, \mathrm{y}}=\frac{\operatorname{Cov}(\mathrm{X}, \mathrm{Y})}{\mathrm{o}_{\mathrm{x}} \cdot \mathrm{o}_{\mathrm{y}}}$ in Excel, where $x$ and $y$ sample mean values of arrays investigated parameters. Here and further that $r$ is correlation coefficient; *, ** and $* * *$ specify in reliability $\tau$ accordingly at $P \leq 0.05,0.01$ and 0.001 [25].

\section{Results and Discussion}

3.1 In vivo Laboratorial Screening of Barley and Wheat for Salt- and Draught-Resistance at the Germination Stage

Suppression of growth processes under draught or salinization conditions are the reason of reduction in yields of cereal crops and thus serve an important criterion contributing to crops sensitivity to abiotic stresses. Relative values of parameters of linear growth under stress in relation to control values are an important estimation parameter in the course of seedlings resistance analysis.

Decrease in parameters of linear growth and biomass gain of the barley and wheat seedlings was observed under modeled draught and salinization conditions. It was noted that primordial roots of seedlings in the experimental version were almost completely free from root fibrils, thus absorption surface of roots decreased severely under stress conditions.

Wheat callus tissue morphology modification and considerable loss of biomass of calluses were noted under stresses. Table 2 shows alteration of plant biomass gain by the example of plant members of seedlings and callus tissues of wheat.

Considerable positive correlation relationships were registered between relative gain of callus biomass and relative increase in number of primordial roots under

Table 2 Relative accumulation of biomass of wheat plant tissues in conditions of osmotic and salt stress in vivo and in vitro, \% to control.

\begin{tabular}{|c|c|c|c|c|c|c|}
\hline \multirow{2}{*}{ Lines } & \multicolumn{3}{|c|}{ Osmotic stress } & \multicolumn{3}{|c|}{ Salt stress } \\
\hline & Roots & Leaves & Calluses & Roots & Leaves & Calluses \\
\hline Akmola 2 & 79.16 & 76.95 & 43.69 & 68.64 & 50.88 & 62.8 \\
\hline Tselinnaya 3C & 72.29 & 74.71 & 20.76 & 105.6 & 93.7 & 34.8 \\
\hline Otan & 78.52 & 76.92 & 23.05 & 75.85 & 83.31 & 39.04 \\
\hline Stepnaya 15 & 87.65 & 82.64 & 23.05 & 83.57 & 68.94 & 58.58 \\
\hline Kazakhstanskaya 10 & 100 & 75.89 & 44.23 & 93.36 & 88.38 & 66.6 \\
\hline Eritrospermum 841 & 67.88 & 68.83 & 15.37 & 54.69 & 46.28 & - \\
\hline
\end{tabular}


simulated draught conditions $-r=0.7 * *$ for wheat and $r=0.67^{* *}$ for barley. Such correlation relationships under salt stress conditions were as well observed $(r=$ $\left.0.5^{*}\right)$. Also correlation relationships between relative gain of callus biomass for barley under impact caused by PEG-6000 and capacity for survival of seedlings under osmotic stress conditions $\left(r=0.75^{* *}\right)$ were registered.

\subsection{Cytological Alterations in Wheat and Barley Cells in Vivo and in Vitro}

Cytological observation of cells of primordial roots under osmotic and salt stress conditions showed a big number of cells with "compressed" cytoplasm in the root cap, in cases of more sensitive species dead cells were observed.

Registered cytological response of primordial roots cells to osmotic and salt stresses are similar (Fig. 1).

Critical period of water consumption for cereal crops falls to the period of male gametes meiosis in pollinium and pollen formation. Due to this reason reproductive cells response to abiotic stresses was of interest for us.

It was noted thereat that plasmolysis advanced identically for wheat and barley; it developed faster in pollen of spikes exposed to artificial draught in comparison with those exposed to artificial salinization.

Thus, the characteristics of plasmolysis development in stressed conditions can serve the basis for cytological characterization of salt- and draught-resistant cereal crops at the level of gametal cells. The results showed that those crops should be deemed draught and salinization resistant and moderately resistant, in which pollen-grains plasmolysis affects less than $50 \%$ of grains registered in the control samples.

In the course of cytological observation of calluses, presence of small iso-diametral cells with dense, rich with organelles cytoplasm and small vacuoles and a large nucleus was registered. The above-mentioned cells were bound in the tissues with larger strongly

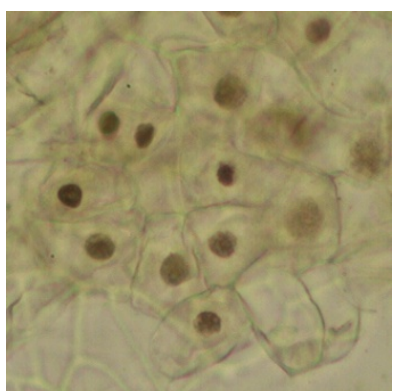

(a)

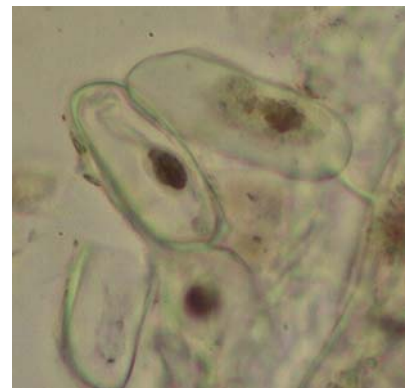

(b)

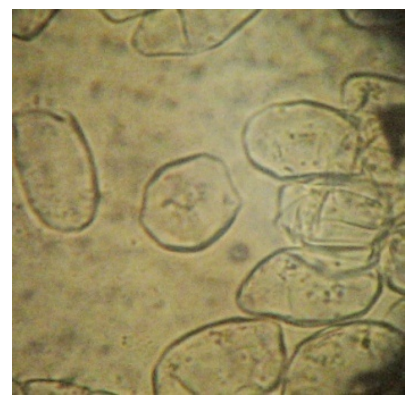

(c)

Fig. 1 Cells of a root cover in 7-days barley germs: (a) control; (b) beginning of plasmolise (stress) process; (c) dead cells (stress) (magn. $\times 10)$.

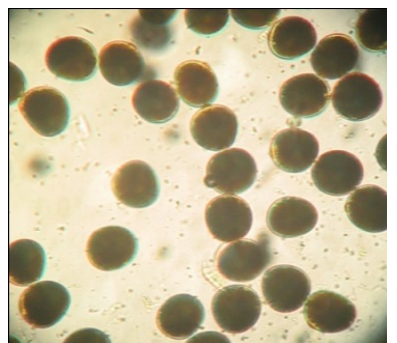

(a)

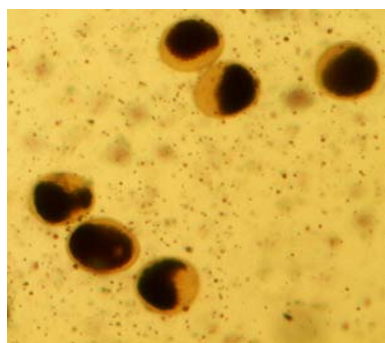

(b)

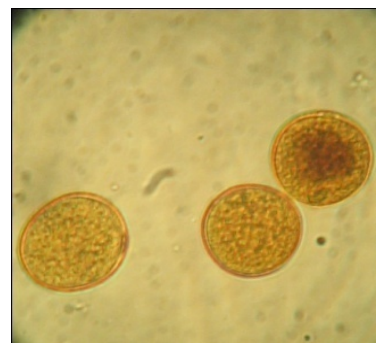

(c)

Fig. 2 Pollen grains: (a) fertile grains (control, magn. $\times 10$ ); (b) pollen grains with strongly expressed plasmolis (stress, magn. $\times 10$ ); (c) sterile grains (stress, magn. $\times$ 40). 
vacuolated cells. Calluses of salt- and draught-resistant genotypes under stresses conditions are close to the control samples in terms of morphology. The rest of calluses in stressed conditions had denser structure, smaller cells, and brighter coloring, this indicates alteration of osmotic characteristics of cells and increase in penetrability of membranes by colorants. It had been registered well-defined plasmolysis in large cells adjacent to embryogenetic areas. Sensitive genotypes demonstrated development of necrotic process (Fig. 3).

In 1939 Nasonov and Alexandrov [26] formulated a theory of nonspecific response of cells to damage. This theory postulates a thesis that despite of a type of disturber and type of cells affected, the response of cells in a number of characteristic features will be uniform.

The in vivo and in vitro experiments with cereal crops cells also revealed commonness of cytological mechanisms of plant cells response to abiotic stress.

\subsection{Alteration of Ion Balance in Vivo and in Vitro under Salt Stress Conditions}

Root cells plasmolysis under salt stress is one of the indicators of membrane permeability alteration. Membrane transport activation is an obvious indicator of membranaceous systems damageability under stress conditions.

Obtained data show a considerable gain of sodium ions content in plant cells together with inhibition and cessation of growth processes in stressed conditions. Moreover, the cells of callus tissue under salt stress accumulate sodium ions is much stronger than the cells of roots and leaves of seedlings. In addition to the observed increase in the content under stress $\mathrm{Na}^{+}$, the data show a tendency to decrease the level of $\mathrm{K}^{+}$in roots, leaves and callus tissues of all genotypes studied. It is noted that in the leaves of resistant genotypes under stress $\mathrm{K}^{+}$content was higher than in the leaves of susceptible lines. In the cells of callus tissue content of potassium ions was significantly higher than in the cells of roots and leaves of seedlings, and the relative decrease in potassium levels during stress was less.

The experiments revealed considerable decrease in $\mathrm{K}^{+} / \mathrm{Na}^{+}$ratio in roots, leaves and callus tissues of barley under $\mathrm{NaCl}$ impact. Resistant specimens had shown these changes in lesser degree. Thus $\mathrm{K}^{+} / \mathrm{Na}^{+}$ ratio under stressed conditions is deemed to be an important and informative parameter as well (Table 3).

The reference data show that level of cytoplasmic sodium, provided that relatively permanent potassium level is maintained, in roots of resistant barley specimens is less, though inconsiderably, than that of sensitive specimens [27]. It is noted that $\mathrm{K}^{+} / \mathrm{Na}^{+}$ratio decreases with salt stress increase and such relation is poorer in roots than in leaves [28]. Suggestion is made that $\mathrm{K}^{+} / \mathrm{Na}^{+}$ratio in cytosol in particular, rather than absolute concentration of $\mathrm{Na}^{+}$, is critical in determining stress level for plants [29, 30]. This

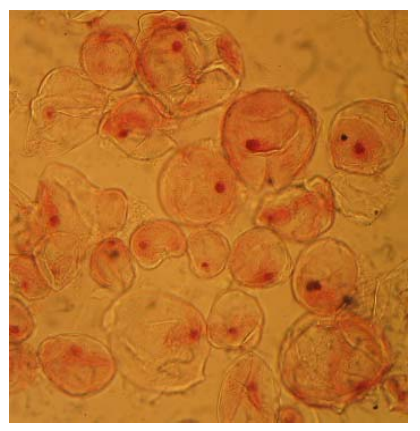

(a)

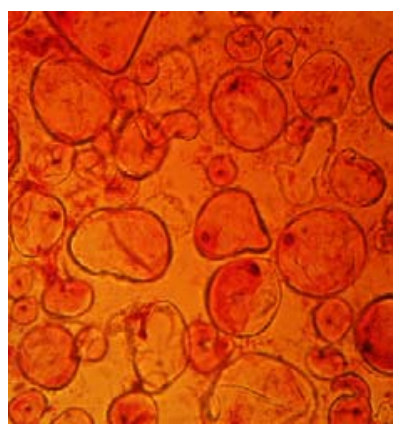

(b)

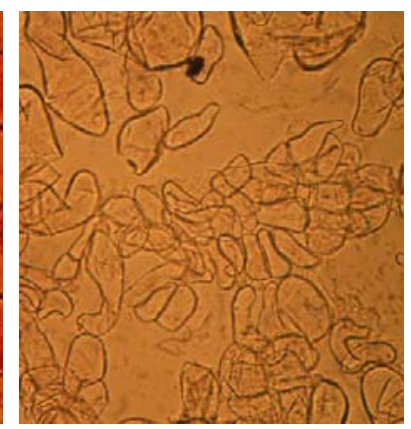

(c)

Fig. 3 Barley callus cells in conditions of salt stress: (a) paranecrosis; (b) necrobios, (c) dead cells $($ magn. $\times$ 40). 
suggestion is proved with the experiments.

3.4 Alteration of Free Proline Content in Vivo and in Vitro under Artificial Draught and Salt Stress Conditions

In the result of experiment, it was discovered that surveyed spring barley genotypes vary considerably in free proline content (Table 4). However, initial level of proline content in callus cells of surveyed genotypes was not related to their field stress resistance. Therefore, the data indicated that proline content in plant cells under normal ambient conditions can not serve as an indicator of their resistance to stress, thus genetic engineering methods, which gain popularity recently, aimed at creation of transgenic plants with initially high proline content, are unlikely to bring principal solution to the abiotic stresses resistance issue.

The most effective parameters of proline formation under stressed conditions according to the experiments are the dynamic relative values of proline accumulation in stressed/control samples.

Plants responses to abiotic stresses are variegated, any event should be considered as a constituent of a group of factors contributing to stress resistance.

Data obtained in the result of experiments positively confirm the relations between proline formation and ion balance in plant cells under salt stress impact. Considerable negative correlation between $\mathrm{K}^{+} / \mathrm{Na}^{+}$ions ratio and percent increase of free proline content in callus tissues of barley was revealed (correlation coefficient $r=-0.97 * * *,-0.84 * * *$ and $-0.56^{* *}$ for the $2 \mathrm{nd}, 3 \mathrm{rd}$, and 4 th week of cultivation respectively).

Japanese scientists, who also noted negative correlation in $\mathrm{K}^{+} / \mathrm{Na}^{+}$ions ratio and proline accumulation in tobacco cells suspension, expressed an opinion that intracellular proline may attenuate inhibition of ferments activity decreasing free radicals content with decrease of $\mathrm{K}^{+} / \mathrm{Na}^{+}$ratio in cells [31].

\subsection{Alteration of Fermentation Capacity in Vivo and in} Vitro under Artificial Draught and Salt Stress Conditions

Reactive oxygen species production in plant cells, such as pro-oxidizing agents and free radicals, causing

Table $3 \mathrm{~K}^{+} / \mathrm{Na}^{+}$ions ratio in roots, leaves and calluses of spring barley under salt stress.

\begin{tabular}{llllll}
\hline Lines & $74 / 2-4$ & St-39 & K-30356 & Rannyi 1 & $75 / 1-5$ \\
\hline Roots & & & & 4.38 & 5.08 \\
\hline Control & 6.27 & 6.12 & 5.09 & 0.05 & 0.08 \\
Saltiness & 0.04 & 0.09 & 0.07 & & 10.0 \\
\hline Leaves & & & & 7.19 & 0.05 \\
\hline Control & 11.67 & 2.08 & 13.73 & 0.07 & 1.03 \\
Saltiness & 0.03 & 0.06 & 0.09 & & 0.74 \\
\hline Calluses & & & & 0.74 & 0.078 \\
\hline Control & 0.98 & - & 0.98 & & \\
Saltiness & 0.087 & - & 0.083 & & \\
\hline
\end{tabular}

Table 4 The content of free proline ( $\mathrm{mg} \%)$ in spring barley calluses under salt and osmotic stresses.

\begin{tabular}{|c|c|c|c|c|c|c|c|c|c|}
\hline \multirow[t]{2}{*}{ Lines } & \multirow[t]{2}{*}{ Field salt-resistance } & \multicolumn{4}{|c|}{ Control (interval, weeks) } & \multicolumn{4}{|c|}{ Saltiness ( $\mathrm{NaCl}, 1.5 \%)$ (interval, weeks) } \\
\hline & & 1 & 2 & 3 & 4 & 1 & 2 & 3 & 4 \\
\hline Rannyi 1 & Resistant & 19.1 & 14.0 & 23.6 & 29.8 & 30.5 & 66.7 & 79.8 & 79.8 \\
\hline \multirow[t]{2}{*}{ K-30356 } & Sensitive & 70.4 & 70.4 & 61.0 & 65.8 & 82.4 & 99.8 & 168.2 & 139.1 \\
\hline & Field drought-resistance & \multicolumn{4}{|c|}{ Control (interval, weeks) } & \multicolumn{4}{|c|}{ Osmotic stress (PEG, 20\%) (interval, weeks) } \\
\hline Dnepr.435 & Resistant & 9.3 & 8.2 & 8.7 & - & 31.9 & 31.3 & 37.9 & - \\
\hline Odessk. 100 & sensitive & 37.2 & 33.5 & 33.6 & - & 49.9 & 47.7 & 50.5 & - \\
\hline
\end{tabular}


Table 5 Relative activity of SOD in wheat calluses under osmotic and salt stresses, \% to control.

\begin{tabular}{llc}
\hline Lines & osmotic stress & salt stress \\
\hline Akmola 2 & 666.7 & 533.3 \\
Tselinnaya 3C & 200.0 & 150.0 \\
Otan & 177.8 & 44.4 \\
Stepnaya 15 & 180.0 & 100.0 \\
Kazakhstanskaya 10 & 194.4 & 83.3 \\
Eritrospermum 841 & 45.5 & 100.0 \\
\hline
\end{tabular}

disturbance of cellular reduction-oxidation status, can be called a "common denominator" of stresses. One of the key roles in antioxidative protection belongs to SOD (superoxide dismutase, EC 1.15.1.1) [32]. In vitro wheat experiments had shown the tendency of increase of SOD fermentation capacity under osmotic stress and its decrease under salt stress (Table 5).

Decrease of SOD fermentation capacity of the resistant genotypes under salt stress conditions was less. Similar results were obtained during in vitro barley experiments.

Consequently these data also prove that relatively high SOD fermentation capacity under salt stress conditions may serve as a cereal crops salt tolerance assessment criterion.

It was noted that increased SOD fermentation capacity of salt-resistant specimens under in vivo salt stress conditions was better pronounced in roots both in barley and wheat crops. SOD fermentation capacity in less resistant genotypes was more pronounced in leave blades (Table 6).

Possible death and necrotic modifications of cells at any level of plants structural arrangement depend on both extent of stress and plant body resistance. While plant body resistance, as seen in the experiments, is composed of many factors, including superoxide dismutase anti-oxidative ferment strength.

Table 6 Relative activity of SOD in barley germ roots and leaves under salt stress, $\%$ to control.

\begin{tabular}{lll}
\hline Lines & Roots & Leaves \\
\hline St-33 & 86.0 & 35.0 \\
К-30356 & 81.8 & 60.0 \\
K-14220 & 50.0 & 20.0 \\
Polarnyi 14 & 35.0 & 55.0 \\
75/1-5 & 25.0 & 55.0 \\
\hline
\end{tabular}

Reference data also show SOD superactivity in salt tolerant genotypes of pea, cotton, tomato and wheat under salt stress conditions [33-36]. SOD activity induction is described by the authors as salt resistance factor of genotypes under examination.

\section{Conclusion}

In studying the reactions of the plant organism to the action of abiotic stressors in the world, a lot of scientific researches in various areas of physiology, and genetics of plants bihimii have been developed. This paper is the attempt to conduct a comprehensive study of the comparative aspect of the cytological, physiological, and biochemical features of the reproductive cells of somatic tissues and intact plants of cereals under the action of osmotic and salt stress at different stages of ontogenesis in vivo and in vitro.

The studies revealed commonality of the basic mechanisms of response to grow-negative cells to the action of osmotic and salt stress in vivo and in vitro.

It is shown that common cytological manifestation of action of abiotic stressors. It was revealed that salt stress and lack of water reduce the viability of pollen, and it was concluded that stress-tolerance of cereals can be estimated from the characteristics of plasmolysis of pollen grains.

New information on the correlative interactions between resistance and abiotic stress at different levels of the organization of the plant indicated the comparability of estimates stress at different levels of plant organization.

Physiological and biochemical indicators of abiotic stresses impact on cells and tissues of cereals, such as SOD fermentation capacity and $\mathrm{K}^{+} / \mathrm{Na}^{+}$ions 
correlation were discovered. These indicators are effective as metabolic markers in the course of testing and selection of stress-resistant cereals in vivo and in vitro.

At the same time, amid a marked loss of generality manifestations described nonspecific reactions to osmotic and salt stress, and showed a significant genotypic diversity of responses studied forms of barley and wheat to drought and salinity, which you can judge the ability of different genomes to regulate itself in extreme conditions, as well as use indicators of genotypic response to abiotic stressors act as a test of determination of stress.

\section{Acknowledgments}

This work has been supported by funds from the National Biology Center of the Republic of Kazakhstan, 10.H (4.3.1./294) project.

\section{References}

[1] M.N. Jithesh, S.R. Prashanth, K.R. Sivaprakash, A. Parida, Antioxidative response mechanisms in halophytes: Their role in stress defence, Genetics 85 (3) (2006) 237-239.

[2] B. Halliwell, J.M.C. Gutteridge, Free Radicals in Biology and Medicine, 4rd ed., Clarendon Press, Oxford, 2006.

[3] R. Serrano, J.M. Mulet, G. Rios, J.A. Marquez, I.F. de Larrinoa, M.P. Leube, et al., A glimpse of the mechanisms of ion homeostasis during salt stress, Experimental Botany 50 (1) (1999) 1023-1036.

[4] P.M. Hasegawa, R.A. Bressan, J.K. Zhu, H.J. Bohnert, Plant cellular and molecular responses to high salinity, Annu. Rev. Plant Mol. Plant Physiol 51 (2000) 463-499.

[5] J. Sun, S. Dai, R. Wang, S. Chen, N. Li, X. Zhou, et al., Calcium mediates root $\mathrm{K}+/ \mathrm{Na}+$ homeostasis in poplar species differing in salt tolerance, Tree Physiol. 129 (9) (2009) 1175-1179.

[6] X. Niu, R.A. Bressan, P.M. Hasegawa, J.M. Pardo, Ion homeostasis in $\mathrm{NaCl}$ stress environments, Plant Physiol. 109 (1995) 735-742.

[7] Y. Terao, Sh. Nakamori, H. Takagi, Gene Dosage Effect of L-proline biosynthetic enzymes on L-proline accumulation and freeze tolerance in saccharomyces cerevisiae, Applied and Environmental Microbiology 69 (11) (2003) 6527-6532.

[8] A.V. Kochetov, S.E. Titov, J.S. Kolodyazhnaya, M.L. Komarova, N.N. Makarova, V.S. Koval, et al.,VIII
International Conference 'The Biology of Plant Cells In vitro and Biotechnology', Abstracts, Saratov, 2003, pp. 146-147.

[9] S.E. Titov, Reception of genetically modified plants of tobacco (Nicotiana Tabacum L.), expressing the ANTISEMANTIC supresor GENE prolinedehydrogenaze. Ph.D. Thesis, Science, Novosibirsk, 2008.

[10] T. Kiyosue, Y. Yoshiba, K. Yamaguchi-Shinozaki, K. Shinozaki, A nuclear gene encoding mitochondrial proline dehydrogenase, an enzyme involved in proline metabolism, is upregulated by proline but downregulated by dehydration in arabidopsis, The Plant Cell 8 (8) (1996) 1323-1335.

[11] T.C. Hsiao, Plant responses to water stress, Annu. Rev., Plant Physiol. 24 (1979) 63-77.

[12] Z. Hong, K. Lakkineni, Zh. Zhang, D.P.S. Verma, Removal of feedback inhibition of *1-Pyrroline-5-carboxylate synthetase results in increased proline accumulation and protection of plants from osmotic stress, Plant Physiol. 122 (2000) 1129-1136.

[13] M. Valko, H. Morris, M.T.D. Cronin, Metals, Toxicity and Oxidative Stress, Current Medicinal Chemistry 12 (10) (2005) 1161-1208.

[14] M. Hagemann, N. Erdmann, Environmental stresses, in: A.K. Rai (Ed.), Cyanobacterial Nitrogen Metabolism and Environmental Biotechnology, Springer-Verlag, Heidelberg, 1997, pp. 156-221.

[15] H. Hayashi, N. Murata, Genetically engineered enhancement of salt tolerance in higher plants, in: K. Sato, N. Murata (Eds.), Stress Responses of Photosynthetic Organisms: Molecular Mechanisms and Molecular Regulation, Elsevier, Amsterdam, 1998, pp. 133-148.

[16] G.V. Udovenko, Diagnostics of plant resistance to stress impacts, Methodical guidance, Leningrad, 1988, p. 89.

[17] N.V. Terletskaya, K.H. Zhambakin, A.R. Iskakov, For laboratory and practical lessons by plant resistance to draught, Methodical instructions, Almaty, 2003, p. 16.

[18] A.K. Gaponenko, N.I. Malikova, G.N. Okhrimenko, A.A. Sozinov, Production of somaclonic lines in crops (Triticum aestivum L. and Hordeum vulgare L.), Reports of the Academy of Sciences of the USSR 283 (1985) 1471-1475.

[19] T.P. Kostyuk, Sh.Sh. Sadykov, R.Sh. Sadykov, A.B. Bigaliev, Equipment for autoclave decomposition of biomaterials which improves the quality of ecologic estimation of environment, Vestnik KazNU, Almaty 1 (9) (2000) 125-127.

[20] L.S. Bates, R.P. Waldern, I.D. Teare, Rapid determination of free proline for water-stress studies, Plant Soil 39 (1973) 205-207.

[21] M. Jiang, J. Zhang, Effect of abscisic acid on active oxygen species, antioxidative defense system and 
oxidative damage in leaves of maize seedlings, Plant Cell Physiology 42 (11) (2001) 1265-1273.

[22] D.A. Trankovsky, Practicum on Plant Anatomy: Textbook for Universities, 3rd ed., Higher school, Moskow, 1979, p. 224.

[23] Z.P. Pausheva, Practicum on plant cytology, Kolos, 1992, p. 267.

[24] B.A. Dospehov, A Field Experiment Technique (with bases of statistical analysis of researches results), 4rd ed., Kolos, Moskow, 1979, p. 416.

[25] P.V. Terent'ev, I.S. Rostova, Workshop on Biometrics, Leningrad, 1977, p. 152.

[26] D.N. Nasonov, V.Ya. Aleksandrov, About reasons of colloidal changes in protoplasm and increase of its relationship to colorants under the influence of damaging impacts, Arkh. anat gistol. Embriol. 22 (1) (1939) 1-43.

[27] D.J. Walker, R.A. Leigh, A. Miller, Potassium homeostasis in vacuolate plant cells, Proc. Natl. Acad. Sci. USA 93 (1996) 10510-10514.

[28] Y. El-Iklil, M. Karrou, R. Mrabet, M. Benichou, Salt stress effect on metabolite concentrations of Lycopersicon esculentum and Lycopersicon sheesmanii, Canadian journal of plant science 82 (1) (2002) 177183.

[29] Y. Guo, F.C. Dong, N. Hu, C.P. Song, Modulation of calcium cytoplasmic membrane potential and absorption of potassium ions in response to salt stress in the root cells of wheat, J. Henan Univ. Natur. Sci. 32 (3) (2002) 25-48.

[30] D.E. Carden, D.J. Walker, T.J. Flowers, A.J. Miller, Single-cell measurements of the contributions of cytosolic $\mathrm{Na}^{+}$and $\mathrm{K}^{+}$to salt tolerance, Plant Physiol. 131 (2003) 676-683.

[31] E. Okuma, K. Soeda, M. Fukuda, M. Tado, Y. Murata, Negative correlation between the ratio of $\mathrm{K}^{+}$to $\mathrm{Na}^{+}$and proline accumulation in tobacco suspension cells, Soil Sci. and Plant Butr. 48 (5) (2002) 753-757.

[32] C. Bowler, M. Van Montagu, D. Inze, Superoxide dismutase and stress tolerance, Annu. Rev. Plant Physiol. Plant Mol. Biol. 43 (1992) 83-116.

[33] D.R. Gossett, E.P. Millhollon, M.C. Lucas, Antioxidant response to $\mathrm{NaCl}$ stress in salt-tolerant and salt-sensitive cultivars of cotton, Crop Sci. 34 (1994) 706-714.

[34] J.A. Hernandez, E. Olmos, F.J. Corpas, F. Sevilla, L.A. del Rýo, Salt-induced oxidative stress in chloroplasts of pea plants, Plant Sci. 105 (1995) 151-167.

[35] Qi Zhi-guang, Huang Zhan-jing, Shtn Yin-zhu, Effect of salt stress in salt-tolerant mutant superoksiddizmutazu in wheat, J. Hebei. Norm. Univ. 26 (4) (2002) 406-409.

[36] V. Mittova, M. Tal, M. Volokita, M. Guy, Up-regulation of the leaf mitochondrial and peroxisomal antioxidative systems in response to salt-induced oxidative stress in the wild salt-tolerant tomato species Lycopersicon pennelli, Plant Cell Environ 26 (6) (2003) 845-856. 